\title{
Behavior of bearing reinforced concrete panels in the process of combined action
}

\author{
Dmitry Korolchenko, ${ }^{1, *}$ \\ ${ }^{1}$ Moscow State University of Civil Engineering, Yaroslavskoe shosse, 26, Moscow, 129337, Russia
}

\begin{abstract}
This research of has important significance in the constructive solution, manufacturing technology and labour costs. The irreversible changes in mechanical properties occur in reinforced concrete elements, decrease in compressive and tensile strength, additional deflections. In this paper, the goal was to assess the behavior of the bearing reinforced concrete panels with a combined action (fire and force) as close as possible to the actual effect in a fire. It was necessary to solve the following tasks: to determine the dependence of deflection and deflection rate on the heating of the plate and the load acting on the panel, to determine the amount of concrete falling before breaking the integrity of the panel (the formation of through cracks, determine the degree of heating of the panel from the duration of fire and force.
\end{abstract}

\section{Introduction}

The bearing reinforced concrete floor panels are widely used in the construction. Wall panels have a number of advantages due to the simplicity of the constructive solution, manufacturing technology and labour costs [1-3]. The main material for the production of single-layer panels is light and cellular concrete [4].

Investigation of the behavior of structures under combined action, namely power and fire, helps to give a more accurate characterization of the structural stability under extreme conditions [5-7]. This issue is relevant because most residential and industrial buildings are built of reinforced concrete structures [8,9]. The heterogeneity of the materials constituting the reinforced concrete, when heated, leads to different temperature deformations, disrupts the bond between cement stone, coarse and fine aggregate and reinforcement. As a result, irreversible changes in mechanical properties occur in reinforced concrete elements, decrease in compressive and tensile strength, additional deflections. There is a sharp decrease in the strength properties of the structure, which leads to its collapse. Moreover, it is difficult to estimate the depth of critical heating of concrete $[10,11]$. This makes it difficult to determine the load-bearing capacity of reinforced concrete elements exposed to fire in case of fire and subsequent cooling. That is not unimportant, because under the influence of high temperature on reinforced concrete construction, concrete and steel reinforcement lose their strength in different ways. This leads to the formation of cracks

\footnotetext{
*Corresponding author: ikbs@mgsu.ru
} 
located along the action of the main stresses and is one of the most dangerous factors that lead to the destruction of structures of concrete.

\section{Materials and methods}

For the experiments were used:

-reinforced concrete panel of mark 2B 300.26.16 and with dimensions (2620hx3000x160) $\mathrm{mm}$

- loading system with a centrally symmetric distributed load consisting of a specially designed and assembled frame

- a vertical furnace for the testing of building structures for fire resistance.

The panel was mounted with a hinged support on a fixed base with the use of a leveling cement-sand mortar with a thickness of at least $20 \mathrm{~mm}$. On the vertical edges of the panel metal stands were installed, not interfering with the deflection of the panel and protecting the panel from falling out of the loading frame during the fire tests. Fastening of the panel to the metal racks through the embedded parts was not carried out, this method of attachment corresponded to the real operating conditions of the panels (Fig. 1).
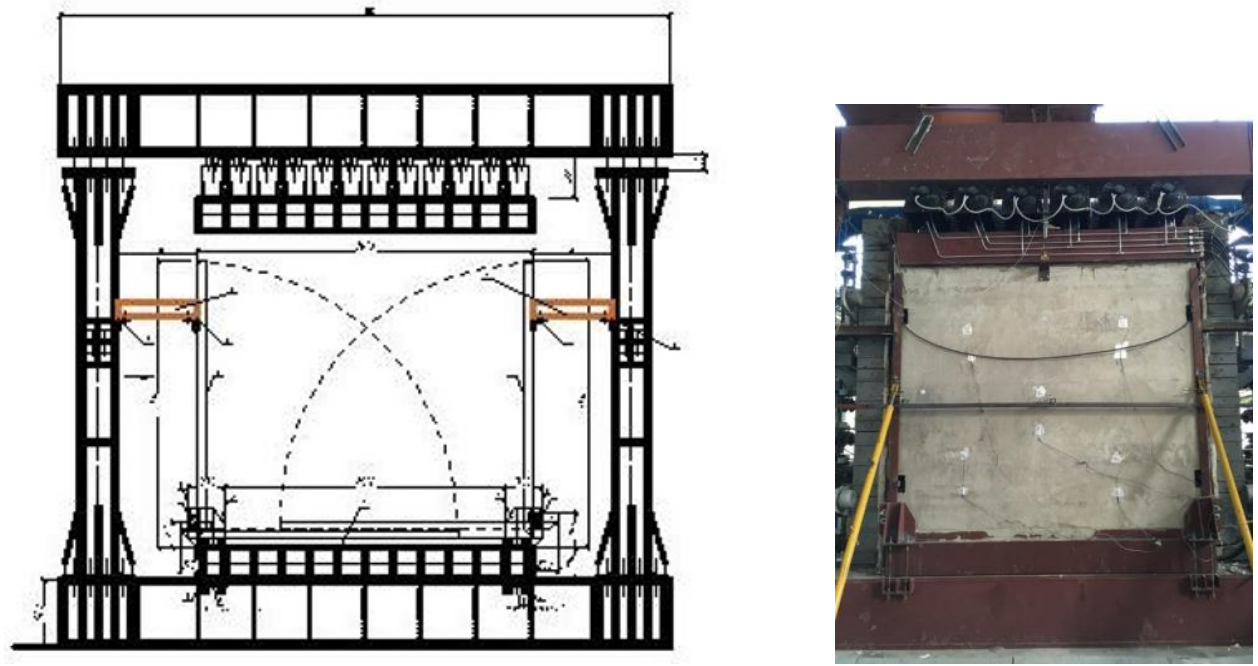

Fig. 1. The scheme of loading test frame.

The value of the force loading on the panel is controlled by the amount of pressure created by the hydraulic system. Vertical movement of the upper end of the test panel is measured by a cable movement sensor (with digital output) installed on the beacon, which is a metal corner rigidly fixed with anchor bolts on the unheated surface of the test panel at the upper end of the panel subjected to the load.

The horizontal movement of the panel (bend / deflection) was measured by displacement sensors installed in the geometric center of the unheated panel surface and at the middle of the height of the test panel at a distance of $100 \mathrm{~mm}$ from the vertical guide rail (metal channel).

The temperature of the outer (unheated) surface of the panel during the fire exposure was recorded using five-point thermocouples mounted on the unheated panel surface in accordance with the requirements of GOST 30247.1. (Fig.2) Several tests were conducted with plates of different types. 


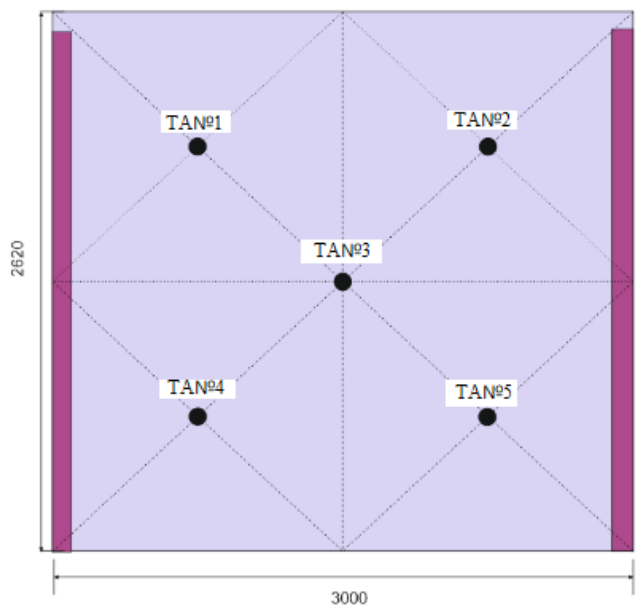

Fig. 2. The scheme of thermocouple arrangement.

Before the beginning of the fire action, the moisture content of the plate, the temperature of the ambient air, and the atmospheric pressure were measured.

After the beginning of the fire action, all changes in the state of the plate were recorded in the worksheet (visual increase in bending, appearance of cracks, moisture, intensity of destruction of concrete, etc.). The change in bending dynamics and the indication of thermoelectric converters were recorded using automated measuring instruments. The time of the beginning of the test and the onset of one of the critical states is fixed. This time is the actual limit of fire resistance. After the test, when the plate has cooled down, the number of cracks and the depth of destruction of concrete are fixed.

\section{Results and discussion}

During the implementation of the combined (fire and force) impact on the panel under test, the deformation of the loaded plate was recorded with the help of a cable sensor.

The maximum rate of deformation of the panel $(0.87 \mathrm{~mm} / \mathrm{min})$ does not exceed the critical strain rate (more than $10 \mathrm{~mm} / \mathrm{min}$.), The fire resistance limit due to the loss of strength of the plate was not fixed (Fig.3).

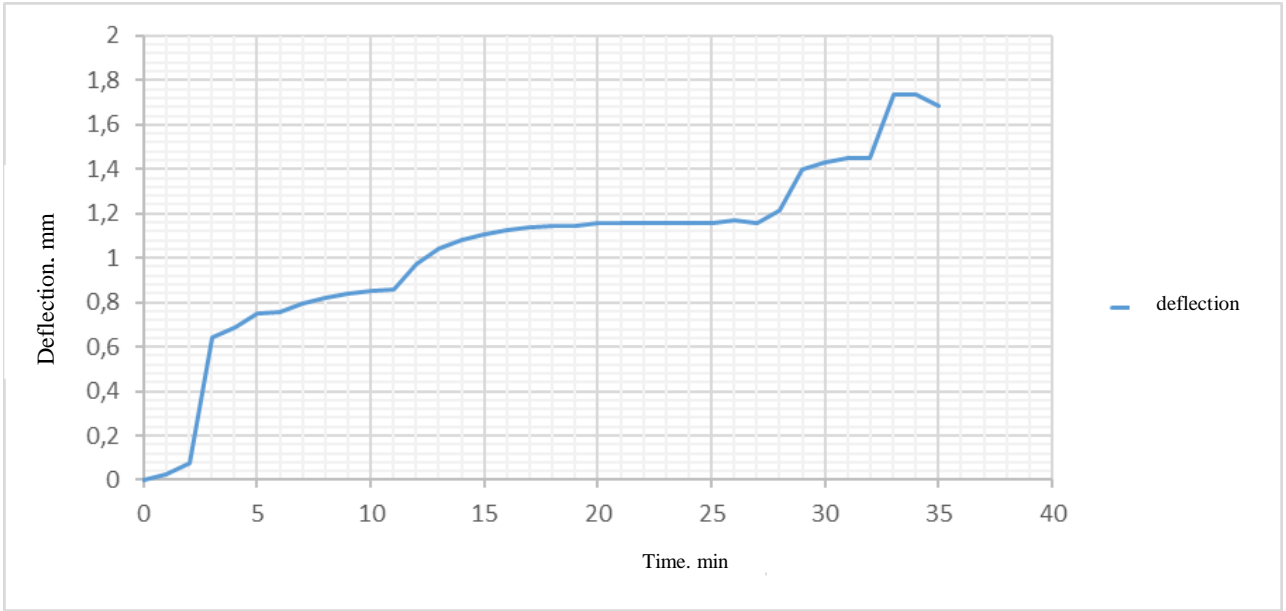

Fig. 3. The graph of change in the panel deformation during sample testing. 
Deformation using a geodetic laser rangefinder. The values of the horizontal movements of the panel (bend / deflection) recorded by the displacement sensors every minute during the fire impact on the plate installed in the geometric center of the unheated panel surface and at the middle of the height of the test panel at a distance of $100 \mathrm{~mm}$ from the vertical guide rail (metal channel) did not exceed the critical values.

The temperature of the outer (unheated) surface of the panel during the fire impact did not exceed the critical value of heating (Fig. 4).

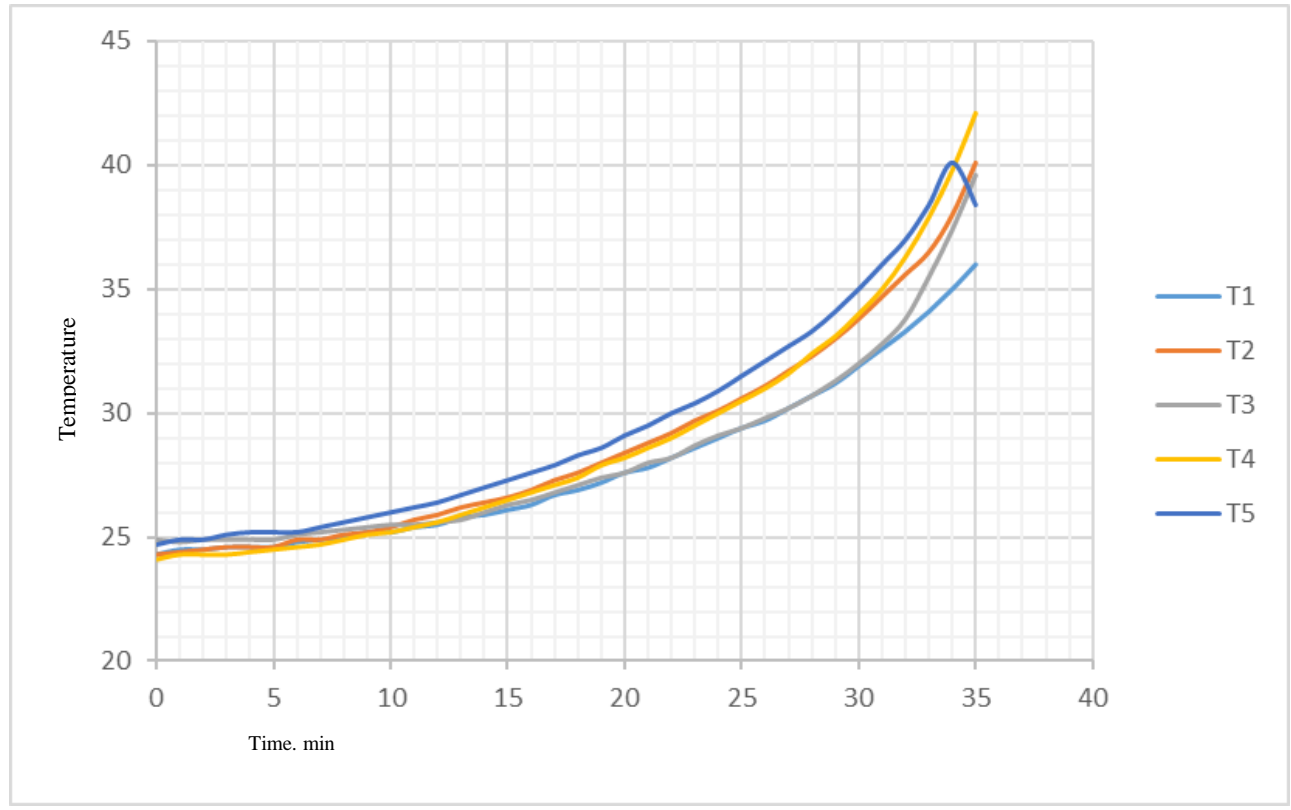

Fig. 4. The graph of the change in the local temperature value of the outer (unheated) panel surface (TEP1-TEP5).

Figure 5 shows the mechanical damage: cracks and chips on the panel.

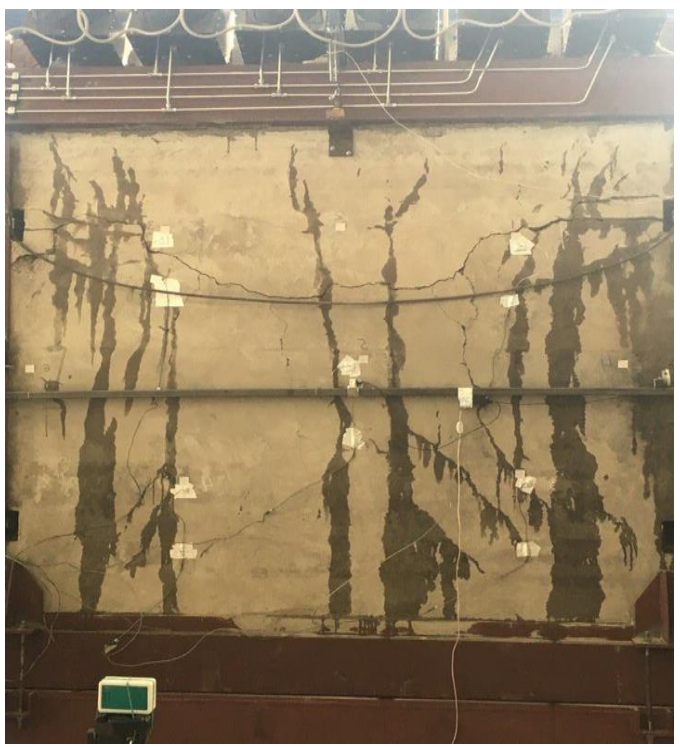

Fig. 5. The panel after the testing. 
During the test on the heated part of the panel, concrete was destroyed. The maximum depth of the destroyed part was $100 \mathrm{~mm}$, while the test was stopped due to the destruction of the panel under load.

\section{Conclusions}

The main reason of the destruction of the panel is the shedding of concrete, which leads to the denudation of the reinforcement, in turn, metal rapidly loses its strength characteristics with a sudden increase in temperature. At the same time, the destruction of concrete was the "shooting off" of small parts from the slab, one of the reasons for the intensity of destruction of the slab was the internal moisture of the concrete.

\section{References}

1. A.A. Gryzin, Tasks and their stability in fires (Prospekt, Moscow, 2008)

2. Yu.M. Lakhtin, Material science tutorial for higher technical educational institutions (Mechanical Engineering, 1999)

3. A.L. Romanov, Properties of building materials and evaluation of their quality (The World of Books, Moscow, 2009)

4. C.B. Aleksandrovsky, Calculation of concrete and reinforced concrete structures for temperature and humidity effects (Stroiizdat, Moscow, 1966)

5. H.H. Brushlinsky, C.B. Sokolov, Fire and explosion safety 1, 7-14 (2003)

6. V.V. Zhukov, Basics of the resistance of concrete under the action of high and high temperatures, Diss. Dr. Tech. sciences (Moscow, 1981)

7. H.A. Il'in, Consequences of fire impact on reinforced concrete structures (Stroyizdat, Moscow, 1979)

8. V.M. Mitasov, M.A. Logunova, N.V. Statsenko, Izvestiya vuzov, Investitsii Stroitelstvo, Real estate 7-1, 77-83 (2017)

9. A.M. Zaitsev, D.S. Chernykh, Fire and explosion safety 7, 14-17 (2011)

10. D.A. Korolchenko, V.A. Kholshchevnikov, MATEC Web of Conferences 106, 12 (2017)

11. Iu. Polandov, D.A. Korolchenko, MATEC Web of Conferences 106, 01040 (2017) 